\title{
Rigidity of elastic shell of rubber-cable belt during displacement of cables relatively to drum
}

\author{
Ivan Belmas ${ }^{1}$, Peter Kogut ${ }^{2}$, Dmytro Kolosov, ${ }^{3, *}$, Volodymyr Samusia ${ }^{3}$, and Serhii \\ Onyshchenko $^{3}$ \\ ${ }^{1}$ Dniprovsk State Technical University, 51918, Kamianske, Dniprobudivska Ave., 2, Ukraine \\ ${ }^{2}$ Oles Honchar Dnipro National University, 49050, Dnipro, Kazakova Str., 18, Ukraine \\ ${ }^{3}$ Dnipro University of Technology, 49005, Dnipro, Yavornytskoho Ave., 19, Ukraine
}

\begin{abstract}
Analytical dependencies for determining the rigidity and parameters of a stress-strain state of a rubber layer located between the cables and the drum from their mutual shear are established in a closed form. A method of determining the dispersion of deviation of calculated displacements from established values of elastic shell material is developed. Obtained results allow considering the shape of an elastic layer of rubber, estimate the level of reliability of the results when calculating a stress-strain state of rubber-cable tractive elements from the shear of cables relatively to the drum. Established dependencies can be used for determining a stress-strain state of a layer of elastic material, caused by shear of cables relatively to the drum of a machine, and formulating the condition of strength of a rubber-cable tractive element loaded with shear forces on a drum. Possibility of determination of a lower boundary of the efficiency coefficient in a process of interaction of a rubber-cable rope (belt) with pulleys and drums, both driving and driven, lined with elastic materials and with hard operating surfaces, allows improving the accuracy of calculations of drives of lifting and transporting machines with such executing elements.
\end{abstract}

\section{Introduction}

Conditions of mineral extraction in mining enterprises are being constantly complicated [13]. Their extraction is performed from considerable depth, the demand in volumes of extracted minerals increase, as well as demand in energy saving [4-6], efficiency and metal consumption of equipment [7-9], including the equipment of lifting and transportation [1012]. Increase of performance and safety parameters serve the purpose of constant development and improvement of designs of modern machines, equipment and mechanisms in the field of mining [13-15], transportation [16-18] and technology [19-21].

Rubber-cable belts and ropes are used as executing elements of lifting machines, powerful conveyors in various branches of mechanical engineering. They are basically loaded with tensile forces directed along the system of parallel cables of the same type, located with a constant spacing in one plane. Structurally, they are connected by a shell of

\footnotetext{
*Corresponding author: evolyuta@gmail.com
} 
elastic material. Both rubber and polyurethane are used as an elastic material. Ropes and belts vary in size of cables, their amount, placement spacing, and elastic shell thickness. The latter combines cables, determines the character of their interaction inside the rope and the interaction of cables with constructive elements of machines, in particular with drums. The elastic shell acts as protection of cables from their interaction with environment and elements of machines. It protects rope and belt cables from corrosion and mechanical wear, increases their lifecycle. The scheme of interaction of a rubber-cable belt with a drum is shown in Figure 1.

The interaction of a tractive element, including a flat rubber-cable belt, with the drum, is accompanied by the action of pressure forces normal to the drum surface and of tangential forces that occur during the transfer of a tractive force from a drum to a belt or as a result of overcoming the moment of resistance of a drum rotation. Consider the influence of shear forces of cables relatively to the drum.

Rope cables with a diameter $d$ are placed with a spacing $t$ and located in a shell made of elastic material with thickness $b$. The displacement of cross-sections of cables relatively to the surface of a drum leads to deformation of an elastic shell. The non-uniform structure of a belt, both along its thickness and its width, leads to uneven deformation. Uneven deformation leads to occurrence of shear stresses in the elastic shell. Determining the distribution of stresses allows choosing the parameters of the belt reasonably; determining the dangerous level of its stress state, what ensures the effectiveness of its use.

\section{State of question and statement of research problem}

Many scientists investigated the issues of determination of a stress-strain state of rubbercable belts and ropes. In paper [22] a method of electric simulation of a stress-strain state of composite materials reinforced by a system of parallel tractive elements is suggested. Durability of butt-joint connections is investigated in paper [23]. In article [24] the expediency of timely detection of conveyor belt damage is justified. In paper [25] the method of finite elements is used to investigate a stress-strain state of a conveyor belt. The dissertation [26] is devoted to increase of durability - time of a lifecycle of butt-joints of conveyor belts, and along with them also the belts themselves. One of the main and most dangerous factors of losing tractive ability by rubber-cable ropes and belts is cable breakages. The influence of breakages of reinforcing elements of the belt is analyzed in paper [27]. Their influence on reduction of a life cycle of butt-joints is proved. In paper [28] a method for determining the values of safe loading on a belt with breakages is justified. It is based on empirical dependencies. Mechanical characteristics of composite materials reinforced by a system of elements of circular cross-section are investigated in [29]. In paper [30], a stressed state of rubber-cable tractive element with a breakage system is investigated. It is proved that the violation of integrity of the extreme cable influences more the redistribution of forces between cables.

The indicated shows that well-known studies of a state of rubber-cable belts do not allow considering the influence of the elastic shell shape on its stress state from the shear of cables relatively to a drum. Establishment of a dependency of the influence of the elastic shell shape on its stressed state due to their shear relatively to a drum is an actual scientific and technical problem.

\section{Methods}

Construction of a model, determination of a stressed state of the elastic material of a deformed shape located between the cables and the drum on shear of cables relatively to the 
drum by methods of linear theory of elasticity. Establishment of analytical dependencies of rigidity and parameters of a stress-strained state of a layer of rubber located between cables and a drum from the shear of cables relatively to the drum in a closed form.

\section{Results and discussion}

Rubber-cable belt has a composite regular structure. The structure regularity allows considering not the entire belt, but only a regularly repeated element. This element consists of a cable that is symmetrically surrounded by an elastic shell. The cable consists of wires twisted into a strand. Strands are twisted along spirals into a single constructive element. As a result, at a macro level, a cable shape is close to a cylinder. A cylinder is axially symmetric. This leads to the fact that a regularly repeated element is a symmetrical figure. This allows dividing it too, and considering only a half of it.

Belts and ropes operate within the limits of elastic deformations. Therefore, the dependency between stresses and deformations is considered linear. Rigidity of the elastic component in a belt is much less than the rigidity of cables. Deformation of cable crosssections is neglected. Elastic shell material is considered isotropic. Conveyor belt is intended for transportation of material. The outer layers of a belt can be subjected to loads caused by the weight of material, the forces of interaction of a belt with structural elements of a conveyor. Neglect these forces. Assume that the elastic material perceives only shear deformation. Shear deformations in the planes normal to cables are small due to significant shear rigidity of cables. Also neglect shear deformations in planes normal to cables. To ensure sufficient adhesion of a belt with a drum, a rope with a pulley, the shell of a belt and a rope is made of material for which the high coefficient of friction is characteristic. A belt (rope) is pressed to a drum (pulley). Friction forces occur between a belt and a drum. They limit the shear of a belt (rope) relatively to a drum (pulley). Assume that a belt (flat rope) is fixedly attached (glued) to a pulley (drum). The belt thickness is not much larger than the diameter cables forming it. The increase of thickness of belts, ropes is connected to the growth of their mass and cost. It is impractical. The conveyor drum diameter, the diameter of a pulley of a lifting machine significantly exceeds diameters of cables and the thickness of a rubber belt (rope). This allows considering a diameter of a drum (pulley) infinitely large.

Use methods of the theory of elasticity. Determine the distribution of stresses in a repeated and symmetrical part of a belt that interacts with the drum through one surface. Belts (ropes) operate within the boundaries of the linear Hooke's law. Consider the symmetric part of a repeated element of the elastic shell. Supplement it with a conditional additional part. Show contours of the conditional additional part of the shell with thin lines in Figure 2.

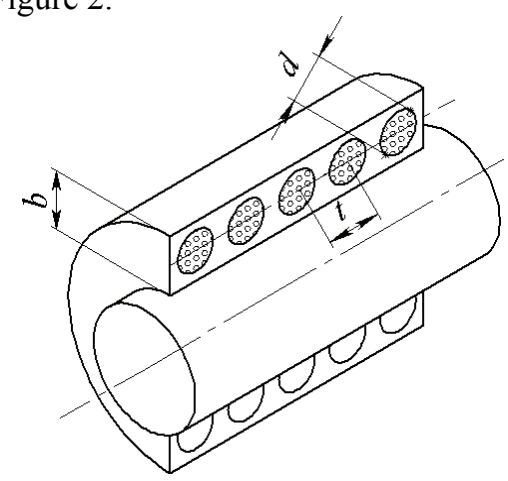

Fig. 1. Scheme of interaction of a rubber-cable belt with a drum.

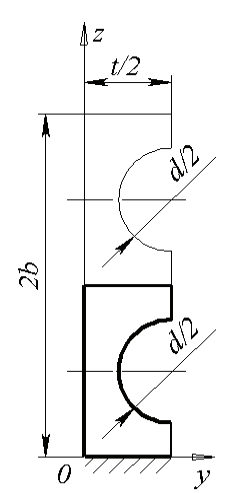

Fig. 2. Computational model of a belt elastic shell during interaction with a drum. 
Formulate the conditions for moving the boundaries of a sample of elastic material. Coordinate $z=0$ corresponds to the plane of a fixed attachment (gluing) of the elastic shell of a belt to the surface of a drum. Movement of the material of a conditional part of the elastic shell with coordinates $z=2 b$ are considered absent. Write down the indicated in a form of the following condition:

$$
\text { when } z=0 \text { or } z=2 b, u=0 .
$$

Surface with $z=b$ is a plane of symmetry of deformation of a sample (Fig. 2). The symmetry of a conditional sample ensures the fulfillment of the condition of absence of tangential stresses on a surface $z=b$.

On a surface with coordinates $y=t / 2$ and $y=0$ external tangential loads do not act. Repeat the indicated with two following conditions:

$$
\begin{array}{ll}
\text { when } y=\frac{t}{2} & \frac{d u}{d y}=0 \\
\text { when } y=0 & \frac{d u}{d y}=0
\end{array}
$$

The surface of interaction of elastic shell material with a cable is considered to be moved by one unit, therefore:

$$
\text { when }\left\{\begin{array}{l}
\left(z-\frac{b}{4}\right)^{2}+\left(y-\frac{t}{2}\right)^{2}=\left(\frac{d}{2}\right)^{2} \\
\left(z-\frac{3 b}{4}\right)^{2}+\left(y-\frac{t}{2}\right)^{2}=\left(\frac{d}{2}\right)^{2}
\end{array}\right\} \quad u=1
$$

Surfaces of the sample $y=\frac{t}{2} \wedge 0 \leq z \leq \frac{b-d}{2}$ and $y=\frac{t}{2} \wedge b-\frac{b-d}{2} \leq z \leq b$ are the symmetry lines. Tangential stresses do not act along these surfaces. Formulate the indicated like this:

$$
\begin{gathered}
\text { when } y=\frac{t}{2} \wedge 0 \leq z \leq \frac{b-d}{2} \quad \frac{d u}{d y}=0, \\
\text { when } y=\frac{t}{2} \wedge b-\frac{b-d}{2} \leq z \leq b+\frac{b-d}{2} \quad \frac{d u}{d y}=0, \\
\text { when } y=\frac{t}{2} \wedge 2 b-\frac{b-d}{2} \leq z \leq 2 b \quad \frac{d u}{d y}=0 .
\end{gathered}
$$

Differential equations of equilibrium of a continuous isotropic material during shear in a plane are determined by Laplace's equation:

$$
\frac{\partial^{2} u}{\partial z^{2}}+\frac{\partial^{2} u}{\partial y^{2}}=0
$$

The solution of Eq. 8 is sought in a form of a product of hyperbolic and trigonometric functions. Considering the conditions Eq. 1 and Eq. 3, they have a form:

$$
u(z, y)=\cosh (y) \sin (z)
$$


Consider the accepted form of solution Eq. 9. To study the mechanism of interaction of rope cables, as its main tractive elements, and the drum, which transmits them this force from a drive of the machine. It is expedient to have a solution in a general form. To obtain a solution in this form, accept $2 b=1$. Values $t, d$ and $u$ consider related to $2 b$. As a result, we have limits of coordinate change $(-1 \leq z \leq 1)$. Write down the functions that specify the boundary conditions by three functions. Define boundary conditions along the surface $y=t / 2$ by the first function $s(z)$ :

$$
s(z)=\left\{\begin{array}{lr}
\frac{4 z b}{t-2 d} & \left(0 \leq z \leq \frac{b-2 d}{4 b}\right) \\
1 & \left(\frac{b-2 d}{4 b} \leq z \leq 1-\frac{b-2 d}{4 b}\right) \\
\frac{(1-z)}{t-2 d} 4 b & \left(1-\frac{b-2 d}{4 b} \leq z \leq 1\right) \\
\frac{4 z}{b-2 d} & \left(0 \geq z \geq-\frac{b-2 d}{4 b}\right) \\
-1 \quad\left(-\frac{b-2 d}{4 b} \geq z \geq-1+\frac{b-2 d}{4 b}\right) & \left(-1+\frac{b-2 d}{4 b} \geq z \geq-1\right)
\end{array}\right\} .
$$

According to a formulated expression, elastic material on the surface $y=b / 2$ has the same displacements as the surface of cables. In a general case, the surface between cables, with exception of points that interact with cables, can have different displacements. These displacements should be symmetrical to a surface that separates the real and the conditional part of the elastic shell. Considering the above-mentioned, define the function $w(z)$ in such a way that it provides a displacement of material between cables in accordance to the fourth part of the sinusoidal period:

$$
w(z)=\left\{\begin{array}{lr}
\frac{4 z}{b-2 d} & \left(0 \leq z \leq \frac{1}{2}-\frac{b-2 d}{4}\right) \\
-\sin \left(\frac{z-\frac{1}{2}+\frac{b-2 d}{4 b}}{b-2 d} 2 b \pi\right) & \left(\frac{1}{2}-\frac{b-2 d}{4} \leq z \leq \frac{1}{2}+\frac{b-2 d}{4}\right) \\
0 & \left(\frac{1}{2}+\frac{b-2 d}{4} \geq z \geq-\frac{b-2 d}{4}\right) \\
\sin \left(\frac{z+\frac{1}{2}-\frac{b-2 d}{4 b} 2 b \pi}{b-2 d}\right) & \left(-\frac{b-2 d}{4} \geq z \geq \frac{b-2 d}{4}-1\right) \\
0 & \left(\frac{b-2 d}{4}-1 \geq z \geq-1\right)
\end{array}\right\} .
$$


The last of the three functions $v(z)$ considers the dependency of displacements of elastic material along the surface, which corresponds directly to surfaces of cables for cases when $y \leq t / 2$. Volumes of the elastic shell material must move along with cables. Note that the first function Eq. 10 defines the unit displacement of points corresponding to cable surfaces when $y=t / 2$. Also consider the accepted form of solution Eq. 9 . Define the displacements on the surface $y=t / 2$ inverse displacements defined via Eq. 9 and referred to displacements in a case $y=t / 2$. Reduce them by one:

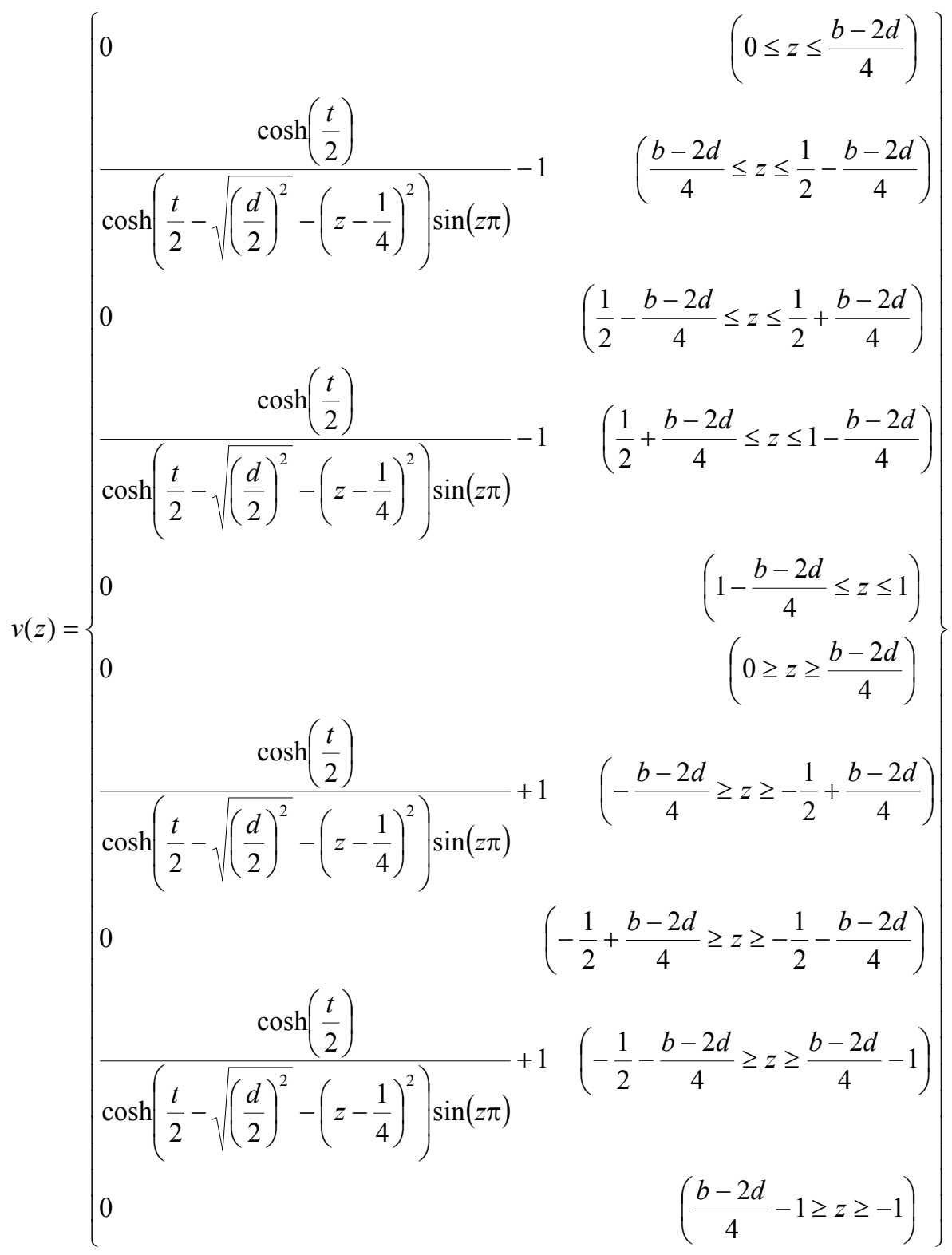

Accepted functions set displacement on the surface $y=t / 2$. They approximately reproduce the displacement of elastic shell material of a rubber-cable belt. The level of proximity can be determined further by comparing the calculated material displacements 
with the accepted - unit.

Develop functions in expressions Eq. 10 - Eq. 12 in the Fourier series by the sines. Write the solution of Eq. 9 in a following form:

$$
u(y, z)=\sum_{m=1}^{M}\left(B S_{m}+C W_{m}+D V_{m}\right) \frac{\cosh \left(q_{m} y\right)}{\cosh \left(q_{m} \frac{t}{2}\right)} \sin \left(q_{m} z\right)
$$

where $B, C, D$ - constant coefficients; $S_{m}, W_{m}, V_{m}$ - coefficients of development of functions $s(z), w(z), v(z)$ in Fourier series; $q_{m}=\pi m ; M$ - number of members in each Fourier series.

Find the values of the coefficients from several conditions. One of conditions assumes a unit displacement of a point of a cable nearest to the surface $y=0$. Perform conditions Eq. 5 - Eq. 7 integrally on the specified surfaces. In doing so, consider the symmetry of their location. This allows reducing the number of conditions to two. In this way, there is a sufficient amount of conditions for determination of three constant coefficients from the system of algebraic equations written in canonical form:

where

$$
\left[\begin{array}{lll}
\alpha_{1,1} & \alpha_{1,2} & \alpha_{1,3} \\
\alpha_{2,1} & \alpha_{2,2} & \alpha_{2,3} \\
\alpha_{3,1} & \alpha_{3,2} & \alpha_{3,3}
\end{array}\right]=\left[\begin{array}{l}
1 \\
0 \\
0
\end{array}\right],
$$

$$
\begin{aligned}
& \alpha_{1,1}=\sum_{m=1}^{M} s_{m} \frac{\cosh \left(\frac{t-d}{2 b}\right)}{\cosh \left(\frac{t}{2 b}\right)} \sin \left(\frac{q_{m}}{4}\right) ; \quad \alpha_{1,2}=\sum_{m=1}^{M} w_{m} \frac{\cosh \left(\frac{t-d}{2 b}\right)}{\cosh \left(\frac{t}{2 b}\right)} \sin \left(\frac{q_{m}}{4}\right) ; \\
& \alpha_{1,3}=\sum_{m=1}^{M} v_{m} \frac{\cosh \left(\frac{t-d}{2 b}\right)}{\cosh \left(\frac{t}{2 b}\right)} \sin \left(\frac{q_{m}}{4}\right) ; \quad \alpha_{2,1}=\sum_{m=1}^{M} s_{m} \frac{\sinh \left(\frac{t}{2 b}\right)}{\cosh \left(\frac{t}{2 b}\right)}\left(\cos \left(\frac{q_{m}(b-2 d)}{4 b}\right)-1\right) \\
& \alpha_{2,2}=\sum_{m=1}^{M} w_{m} \frac{\sinh \left(\frac{t}{2 b}\right)}{\cosh \left(\frac{t}{2 b}\right)}\left(\cos \left(\frac{q_{m}(b-2 d)}{4 b}\right)-1\right) \\
& \alpha_{2,3}=\sum_{m=1}^{M} v_{m} \frac{\sinh \left(\frac{t}{2 b}\right)}{\cosh \left(\frac{t}{2 b}\right)}\left(\cos \left(\frac{q_{m}(b-2 d)}{4 b}\right)-1\right) \\
& \alpha_{3,1}=\sum_{m=1}^{M} s_{m} \frac{\sinh \left(\frac{t}{2 b}\right)}{\cosh \left(\frac{t}{2 b}\right)}\left(\cos \left(\frac{q_{m}}{2}\right)-\cos \left(q_{m}\left(\frac{1}{2}-\frac{b-2 d}{4 b}\right)\right)\right)
\end{aligned}
$$




$$
\begin{aligned}
& \alpha_{3,2}=\sum_{m=1}^{M} w_{m} \frac{\sinh \left(\frac{t}{2 b}\right)}{\cosh \left(\frac{t}{2 b}\right)}\left(\cos \left(\frac{q_{m}}{2}\right)-\cos \left(q_{m}\left(\frac{1}{2}-\frac{b-2 d}{4 b}\right)\right)\right) ; \\
& \alpha_{3,3}=\sum_{m=1}^{M} v_{m} \frac{\sinh \left(\frac{t}{2 b}\right)}{\cosh \left(\frac{t}{2 b}\right)}\left(\cos \left(\frac{q_{m}}{2}\right)-\cos \left(q_{m}\left(\frac{1}{2}-\frac{b-2 d}{4 b}\right)\right)\right) .
\end{aligned}
$$

As a result of solving the system of Eq. 14, the values of unknown constants are obtained:

$$
\begin{gathered}
D=\frac{\alpha_{2,1} \alpha_{3,2}-\alpha_{3,1} \alpha_{2,2}}{\alpha_{3,3}\left(\alpha_{2,2} \alpha_{1,1}-\alpha_{2,1} \alpha_{1,2}\right)+\alpha_{2,3}\left(\alpha_{3,1} \alpha_{1,2}-\alpha_{3,2} \alpha_{1,1}\right)+\alpha_{1,3}\left(\alpha_{3,2} \alpha_{2,1}-\alpha_{3,1} \alpha_{2,2}\right)}, \\
C=\frac{\alpha_{2,1}+D\left(\alpha_{1,3} \alpha_{1,1}-\alpha_{3,1} \alpha_{2,1}\right)}{\alpha_{1,2} \alpha_{2,1}-\alpha_{2,2} \alpha_{1,1}}, B=\frac{1-C \alpha_{1,3}-D \alpha_{2,1}}{\alpha_{1,1}} .
\end{gathered}
$$

With the use of determined unknown constants distributions of deformations and tangential stresses are obtained. The results are given below for relative displacements (unit), the dimensions of an elastic belt shell. Figure 3 shows a definite form of an elastic shell in a case of displacement of a cable cross-section by one unit.

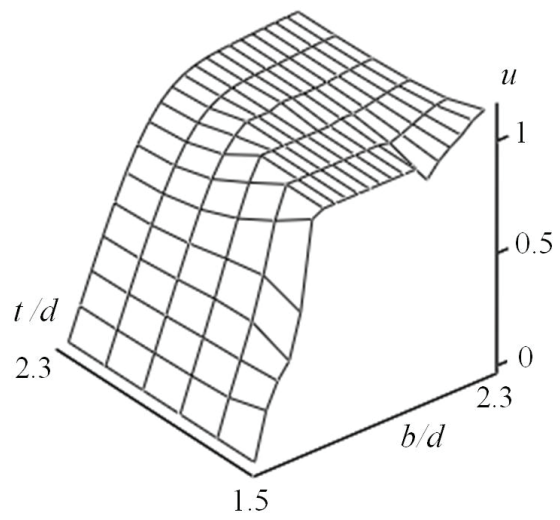

Fig. 3. The shape of an elastic shell part acquired as a result of axial displacement of a cable by one unit.

Note that in the figure, a part of the formed shape within the boundaries corresponding to a cable cross-section is conditionally given equal to one. The obtained displacements of points of a cross-section of the elastic material correspond to the idea of a character of its deformation in a case of displacement of a cable cross-section by one unit. Divide half of the circle, which outlines the contour of a half of cross-section of a cable, into $M$ equal parts. The different amount of points can be selected. According to formula Eq. 13 for each point on the half arc of the circle determine the calculated displacements. For the found base of values of displacements determine the deviation dispersion of these values from a unit. Results for various values of a relative belt thickness and cable placement spacing in it are shown in Figure 4. 
Graphical distribution indicates that the value of dispersion increases with increasing relative values of a spacing $(t / d)$ and belt thickness $(b / d)$. In practice, lifting rubber-cable ropes with minimum ratios of rope thickness and cable placement spacing to their diameters are used. Relative thickness and cable placement spacing in rubber-cable ropes, as a rule, do not exceed 2.3. The indicated shows the possibility of calculating the deformed and, accordingly, stress state of rubber-cable ropes and belts with a certain level of reliability of obtained results.

Tangential stresses, in accordance with Hooke's linear law, are proportional to the shear modulus and a shear angle tangent. The first depends on the material, the second on the mutual displacement of the material volume. Determine the characteristics of the mutual displacement. Differentiate the expression Eq. 13 by $d z$ and $d y$. Note that they are constructed for a unit of relative displacement and relative dimensions of the elastic shell of a belt:

$$
\begin{gathered}
\frac{u(y, z)}{d y}=\sum_{m=1}^{M}\left(B S_{m}+C W_{m}+D V_{m}\right) \frac{\Delta \sinh \left(q_{m} y\right)}{2 \cosh \left(q_{m} \frac{t}{2}\right) b} \sin \left(q_{m} z\right) q_{m}, \\
\frac{u(y, z)}{d z}=-\sum_{m=1}^{M}\left(B S_{m}+C W_{m}+D V_{m}\right) \frac{\Delta \cosh \left(q_{m} y\right)}{2 \cosh \left(q_{m} \frac{t}{2}\right) b} \cos \left(q_{m} z\right) q_{m},
\end{gathered}
$$

where $\Delta$ - cable displacement during a mutual shear of cables.

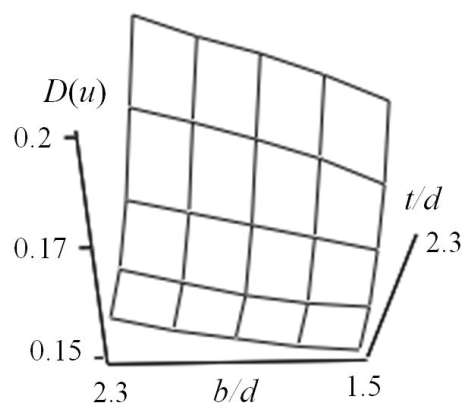

Fig. 4. Dependency of the dispersion of displacements of points of an elastic shell located on an arc with a radius of a cable $(d / 2)$

Determine the tangents of shear angles for the boundary $z=0$ - plane of symmetry of a location of mutually sheared cables:

$$
\frac{u(y, z=0)}{d z}=-\sum_{m=1}^{M}\left(B S_{m}+C W_{m}+D V_{m}\right) \frac{\Delta \cosh \left(q_{m} y\right)}{2 \cosh \left(q_{m} \frac{t}{2}\right) b} q_{m} .
$$

Stresses by the Hooke's law:

$$
\tau=-G \sum_{m=1}^{M}\left(B S_{m}+C W_{m}+D V_{m}\right) \frac{\Delta \cosh \left(q_{m} y\right)}{2 \cosh \left(q_{m} \frac{t}{2}\right) b} q_{m} .
$$

Find a definite integral from tangential stresses by $d y$ between a zero and $t / 2$. During 
this, consider that, using Hooke's law, determine the force required to displace the rope cables by the value $\Delta$ in a sample of a unit length - the size determined in a direction of the cable:

$$
T=G \Delta \sum_{m=1}^{M}\left(B S_{m}+C W_{m}+D V_{m}\right) \frac{\sinh \left(q_{m} \frac{t}{2}\right)}{\cosh \left(q_{m} \frac{t}{2}\right)} .
$$

The resulting value of a force to displace one cable by the value $\Delta=1$ is the value of shear rigidity of a part of an elastic shell with width $t$.

The quantity inverse to shear force:

$$
c=\frac{1}{G}\left[\sum_{m=1}^{M}\left(B S_{m}+C W_{m}+D V_{m}\right) \frac{\sinh \left(q_{m} \frac{t}{2}\right)}{\cosh \left(q_{m} \frac{t}{2}\right)}\right]^{-1} .
$$

The results of a calculation of forces are shown in the following figure (Fig. 5).

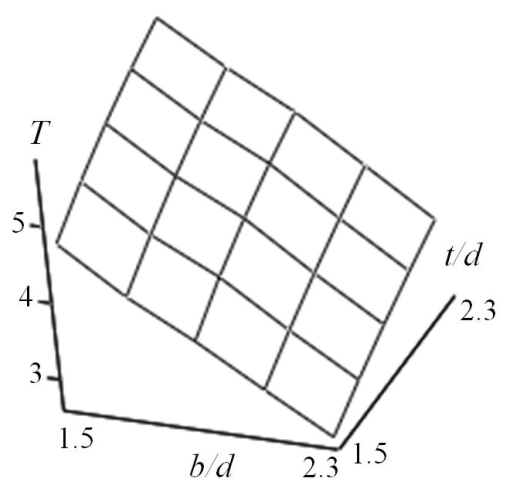

Fig. 5. Dependency of relative shear force of cables $(T)$ on the belt thickness and a placement spacing of cables related to their diameter in a belt.

According to Figure 5, the growth of a relative thickness of a belt leads to a decrease in a force of deformation. At the same time, the growth of a placements spacing of cables leads to an increase of indicated force. Changes in the latter are smaller. This is a consequence of the influence of two factors on a stress state of an elastic material. The first factor is a growth of sample sizes, which reduces its rigidity. Action mechanism of this factor is the same for both cases. The second factor in a mechanism of influence of a sample size on its rigidity is the uneven distribution of deformations, and respectively, of stresses, in a direction of placement of cables.

The stress state depends on its distribution in the material. The main characteristic of distribution of stress is a concentration coefficient. The analysis of distributions of stress concentration coefficients indicates their qualitative coincidence with a dependency of shear force of cables relatively to a drum.

Above, the interaction of a rubber-cable belt with a hard drum is considered. In practice, drum conveyors are used; pulleys of lifting machines are covered with elastic materials (lined). The elastic lining material can be considered as part of a rope shell and the results obtained for belts that interact with lined drums can be applied. In a case of using the 
materials with different mechanical properties, their mechanical characteristics may be averaged, for example, according to Voigt.

In a process of cable displacement, associated with a transfer of a tractive force to the cables, the machine drive energy is spent on useful work, and work associated with pulley rotation, and deformation of an elastic shell. The work associated with a pulley rotation depends on the design of pulley supports. It is investigated, that the energy loss on it is considered through the efficiency coefficient. Useful work is considered equal to a product of the cable cross-section displacement and the cable tension force related to free fall acceleration.

Assume that the cable is at a distance $R$ from a pulley axis. It bends around it along the angle of contact $\varphi$. The tension of a cable part that runs on the pulley is $T$. The tension of a part that runs off is $T-\Delta T$.

$$
R=R_{p}+b / 2
$$

where $R_{p}$ - pulley radius.

After the drum turns by the angle $\varphi$ the end of a cable part that runs on the pulley displaces by a magnitude:

$$
\delta=R \varphi-\Delta-\varepsilon,
$$

where $\Delta-$ a displacement of a rubber shell caused by a shear of cables relatively to the pulley; $\varepsilon$ - cable displacement in a cross-section of its running on the pulley relatively to a cross-section of running off.

Cable displacement relatively to a pulley is determined by using a dependency Eq. 18 . In this case, consider that the shear force is equal to a difference of forces of running-on and running-off $T-\Delta T$. Deformations along the length vary from minimum to maximum. The length of shear part is $R \varphi$ :

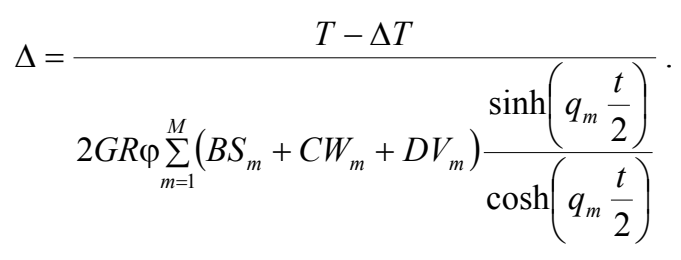

Cable displacement in a cross-section of its running on the pulley relatively to a crosssection of running off is a consequence of change of cable tension. Define it according to Hooke's law:

$$
\varepsilon=R \varphi \frac{T-\Delta T}{E F}
$$

where $E$ - is a reduced modulus of elasticity of a cable to tension; $F$ - cable crosssection.

Displacement $\varepsilon$ and $\Delta$ are associated with periodic deformation of an elastic shell. Much of the energy dissipates in a process of deformation of elastic materials. Assume that the energy of an elastic shell completely dissipates. Determine the lower boundary of efficiency coefficient in a process of interaction of rubber-cable rope (belt) with a driving drum as a relation of displacements: 


$$
\eta=\frac{R \varphi-\Delta-\varepsilon}{R \varphi}
$$

Obtained values can be also used for lined and non-lined polyspasts of pulleys, interaction with which leads to a difference in tension of cables in rubber-cable ropes and belts.

\section{Conclusions}

Deformed state of an elastic shell of a flat rubber-cable tractive element caused by displacement of cables relatively to the drum is given by a sum of three states. The first state is presented as constant. Two others consider the features of deformation along the surface that interacts with a cable and the outer surface of the shell that is not loaded. The level of reliability of the model is estimated by determining the dispersion of deviation of model shear along the arc of interaction of shell material and a cable from one unit.

Rigidity and a stress state of an elastic shell depend on geometrical parameters of a cross-section of a rubber-cable belt and rope. Growth of relative thickness of a belt leads to a decrease in rigidity. At the same time, an increase of cable placement spacing leads to its growth.

A model of the deformed state of an elastic shell of a flat rubber-cable tractive element caused by the shear of cables relatively to a drum and its stress state is determined by the methods of linear theory of elasticity. Analytical dependencies of rigidity, parameters of a stress-strain state of a layer of elastic shell material are obtained in a closed form, what can be used in mathematical models of equilibrium of cables in rubber-cable conveyor belts and flat ropes and in determining the condition of strength, what increases the safety of use of belts and ropes, analysis of their technical condition during operation to increase their life cycle.

Obtained results allow considering the shape of an elastic layer, estimate a level of reliability of the results in calculations of a stress-strain state of rubber-cable tractive elements during the interaction with drums. The elastic lining material can be considered as part of a belt shell and use the obtained results for belts that interact with lined drums. The lower boundary of the efficiency coefficient is determined in a process of interaction of a rubber-cable rope (belt) with pulleys and drums, that are driving and driven, lined with elastic materials and with hard operating surfaces, what allows improving the accuracy of calculations of drives of lifting and transporting machines with such executing elements.

\section{References}

1. Babets, D.V., Sdvyzhkova, O.O., Larionov, M.H., Tereshchuk, R.M. (2017). Estimation of rock mass stability based on probability approach and rating systems. Naukovyi Visnyk Natsionalnoho Hirnychoho Universytetu, (2), 58-64

2. Khomenko, O., Kononenko, M., Bilegsaikhan, J. (2018). Classification of Theories about Rock Pressure. Solid State Phenomena, (277), 157-167. DOI: 10.4028/www.scientific.net/SSP 277.157

3. Vladyko, O., Kononenko, M., Khomenko, O. (2012). Imitating modeling stability of mine workings. Geomechanical Processes During Underground Mining 2012, 147-150. DOI: $10.1201 / \mathrm{b} 13157-26$

4. Pivnyak, G., Samusia, V., Oksen, Y., Radiuk, M. (2014). Parameters optimization of heat pump units in mining enterprises. Progressive Technologies of Coal, Coalbed Methane, and Ores Mining, 19-24 
5. Krasovskiy, P., Tsyplenkov, D., Nesterova, O. (2013). Operating dynamics of parameters and technical losses in the components of power supply systems. Energy Efficiency Improvement of Geotechnical Systems - Proceedings of the International Forum on Energy Efficiency, 113-119

6. Sadovenko, I., Rudakov, D., Inkin, O. (2014). Geotechnical schemes to the multipurpose use of geothermal energy and resources of abandoned mines. Progressive Technologies of Coal, Coalbed Methane, and Ores Mining, 443-450

7. Bazhenov, V.A., Gulyar, A.I., Piskunov, S.O., Andrievskii, V.P. (2013). Design life assessment of the blade root of a gas turbine unit under thermomechanical loading. Strength of Materials, 45(3), 329-339. DOI: 10.1007/s11223-013-9463-0

8. Chigirinsky, V., Putnoki, A. (2017). Development of dynamic model of transients in mechanical systems using argument-functions. Easten-European Journal of Enterprise Technologies, Vol. 3, 7(87), 11-22. DOI: 10.15587/1729-4061.2017.101282

9. Bazhenov, V.A., Gulyar, A.I., Piskunov, S.O., Shkryl, A.A. (2006). Life assessment for a gas turbine blade under creep conditions based on continuum fracture mechanics. Strength of Materials, 38(4), 392-397. DOI: 10.1007/s11223-006-0055-0

10. Bondarenko, V.I., Samusya, V.I., Smolanov, S.N. (2005). Mobile lifting units for wrecking works in pit shafts. Gornyi Zhurnal, (5), 99-100

11. Belmas, I., Kolosov, D. (2011). The stress-strain state of the stepped rubber-rope cable in bobbin of winding. Technical and Geoinformational Systems in Mining: School of Underground Mining 2011, 211-214

12. Denyshchenko, O., Shyrin, A., Rastsvietaiev, V., Cherniaiev, O. (2018). Forming the structure of automated system to control ground heavy-type ropeways. Naukovyi Visnyk Natsionalnoho Hirnychoho Universytetu, (4), 79-85. DOI: 10.29202/nvngu/2018-4/12

13. Kolesnik, V.Ye., Kulikova, D.V., Pavlichenko, A.V. (2016). Substantiation of rational parameters of perforated area of partitions in an improved mine water settling basin. Naukovyi Visnyk Natsionalnoho Hirnychoho Universytetu, (6), 120-127

14. Kolosov, D., Dolgov, O., Kolosov, A. (2014). Analytical determination of stress-strain state of rope caused by the transmission of the drive drum traction. Progressive Technologies of Coal, Coalbed Methane, and Ores Mining, 499-504

15. Loveikin, V.S, Romasevych, Yu.O. (2017). Dynamic optimization of a mine winder acceleration mode. Naukovyi Visnyk Natsionalnoho Hirnychoho Universytetu, (4), 5561

16. Franchuk, V.P., Ziborov, K.A., Krivda, V.V., Fedoriachenko, S.O. (2017). On wheel rolling along the rail regime with longitudinal load. Naukovyi Visnyk Natsionalnoho Hirnychoho Universytetu, (3), 62-67

17. Kravets, V., Sakhno, V., Bas, K., Kravets, V. (2018). Program spatial movement of high-speed vehicles. In: IOP Conf. Ser.: Mater. Sci. Eng. 383 012032. DOI: 10.1088/1757-899X/383/1/012032

18. Ziborov, K., Fedoriachenko, S. (2015). On influence of additional members' movability of mining vehicle on motion characteristics. New Developments in Mining Engineering 2015: Theoretical and Practical Solutions of Mineral Resources Mining, 237-241

19. Filimonikhin, G., Olijnichenko, L. (2015). Investigation of the possibility of balancing aerodynamic imbalance of the impeller of the axial fan by correction of masses. Eastern-European Journal of Enterprise Technologies, 5,7(77), 30-35. DOI: 10.15587/1729-4061.2015.51195

20. Chigirinsky, V.V., Legotkin, G.I., Slepynin, A.G., Kozlov, V.I., Dragobetsky, V.V. (2015). Mechanisms of plastic deformation in case of production of thin-walled rolled stock of the special purpose. Metallurgical and Mining Industry, (11), 222-230

21. Filimonikhin, G., Filimonikhina, I., Yakymenko, M., Yakimenko, S. (2017). Application of the empirical criterion for the occurrence of auto-balancing for 
axisymmetric rotor on two isotropic elastic supports. Eastern-European Journal of Enterprise Technologies, 2, 7(86), 51-58. DOI: 10.15587/1729-4061.2017.96622

22. Kolosov, L.V., Bel'mas, I.V. (1981). Use of electrical models for investigating composites. Mechanics of Composite Materials, 17(1), 115-119

23. Marasová, D., Ambriško, L., Andrejiová, M., Grinčová, A. (2017). Examination of the process of damaging the top covering layer of a conveyor belt applying the FEM. Journal of the International Measurement Confederation, (112). 47-52. DOI: 10.1016/j.measurement.2017.08.016

24. Blazej, R., Jurdziak, L., Burduk, R., Kirjanow, A., Kozlowski, T. (2017). Analysis of core failure distribution in steel cord belts on the cross-section. International Multidisciplinary Scientific GeoConference Surveying Geology and Mining Ecology Management, 17(13), 987-994. DOI: 10.5593/sgem2017/13/S03.125

25. Song, W., Shang, W., Li, X. (2009). Finite element analysis of steel cord conveyor belt splice. ET Conference Publications, 2009(556). DOI: 10.1049/cp.2009.1415

26. Levchenya, Zh.B. (2004). Povyshenie nadezhnosti stykovykh soedineniy konveyernykh lent na gornodobyvayushchikh predpriyatiyakh: Na primere RUP "PO "Belaruskaliy" Ph.D. MGOU

27. Tantsura H.I. (2010). Gnuchki tyagovi organy. Stikovi zyednannya konveyernykh strichok. Dniprodzerzhins'k: DDTU

28. Volokhovskiy V.Yu., Radin V.P., Rudyak M.B. (2010). Kontsentratsiya usiliy v trosakh i nesushchaya sposobnost' rezinotrosovykh konveyernykh lent s povrezhdeniyami. $M E I$ Bulletin, (5), 5-12

29. Dariya Zade S. (2013). Chislennaya metodika opredeleniya effektivnykh kharakteristik odnonapravleno armirovannykh kompozitov. Bulletin NTU "KhPI", (58), 71-77

30. Bel'mas, I.V. (1993). Stress state of rubber-rope tapes during their random damages. Problemy Prochnosti i Nadezhnos'ti Mashin, (6), 45-48 